\title{
PAISAGENS RURBANAS: A TENSÃO ENTRE PRÁTICAS RURAIS E VALORES URBANOS NA MORFOGÊNESE DOS ESPAÇOS PÚBLICOS DE SEDES DE MUNICÍPIOS RURAIS. UM ESTUDO DE CASO
}

\section{Rurban Landscapes: tension between rural practices and urban values in the morphogenesis of public spaces of seats of rural municipalities. A case study}

Gisela Barcellos de Souza Doutoranda em Arquitetura e Urbanismo pela Universidade de São Paulo Professora Efetiva da Universidade Estadual de Maringá Maringá/PR - Brasil gbsouza2@uem.br

Artigo recebido para publicação em 22/04/09 e aceito para publicação em 14/07/09

RESUMO: O presente artigo interessa-se pelo esmaecimento das fronteiras entre o rural e o urbano na sede de pequenos municípios rurais. A partir de um estudo de caso - um municipio de menos de 3 mil habitantes -, postula-se que a inadequação da denominação destas sedes pequenos municípios rurais como "cidade" não seja inócua; esta seria capaz de engendrar profundas modificações no espaço distrital e em suas representações, possibilitando, através da inscrição no território de valores urbanos e de práticas rurais, a configuração de uma paisagem rurbana.

Palavras-chave: Paisagem rurbana. Sede de pequeno município rural. Morfogênese.

ABSTRACT: This article is interested in the deterioration of limits between rural and urban spaces in seats of small rural municipalities. Based in a case study - a city of less than 3 thousand inhabitants - this article postulates that the inadequate nomination of the seat of smaller rural municipalities as a "city" could to generate profound changes in townscape and in theirs representations, which by the inscription of urban values and rural practices in its territory allows the configuration of a rurban landscape.

Keywords: Rurban landscape. Seat of small rural municipality. Morphogenesis.

\section{INTRODUÇÃO}

Entre os espaços rurais e urbanos observa-se que as fronteiras esmaecem, seus contornos, outrora nítidos, borram-se, tornam-se imprecisos; dilatam-se e esfacelam-se em inúmeras situações intermediárias. Frente a este fenômeno, cuja manifestação tornou-se passível de reconhecimento, sobretudo, nas últimas décadas do século XX (SECCHI, 2006), o antagonismo entre as noções de ruralidade e urbanidade - definidas pela sociologia americana no início do século XX como categorias socioculturais antitéticas e relativas a espaços distintos - parece inapropriado. Por um lado, cidades tomam proporções territoriais, dificultando o discernimento de seus limites e colocando em cheque, com sua dispersão, o critério da concentração 
Paisagens rurbanas: a tensão entre práticas rurais e valores urbanos na morfogênese dos espaços públicos de sedes de Municípios rurais. Um estudo de caso

Gisela Barcellos de Souza

como propriedade imprescindível para que se forje a definição de espaço urbano (SIEVERTS, 2004). No outro extremo, a minimização do isolamento do espaço rural diante da ampliação e da intensificação das redes de transporte e de informação, aliada ao ritmo acelerado de transformações nas relações de trabalho no setor de produção agropecuária, impossibilita a identificação das características socioculturais que correspondiam à noção de ruralidade (CARNEIRO, 1998).

Tais transformações manifestam-se no território, alteram a maneira como este é percebido, redefinem as relações socioculturais que nele se estabelecem. Entre os diversos cenários possíveis de análise a partir desta relação ambígua entre o rural e o urbano, o centro de interesse deste artigo encontra-se no extremo oposto ao fenômeno chamado de "metrópole dispersa"; ou seja, abordar-se-á o espaço urbano da sede de municípios rurais. Postula-se a hipótese de que a inadequação, apontada por Veiga (2001), da denominação das sedes destes municípios como "cidade" não seja inócua; esta seria capaz de engendrar profundas modificações no espaço distrital e em suas representações, possibilitando, através da inscrição no território de valores urbanos - reforçados pela presença de instituições da esfera municipal - e de práticas rurais, a configuração de uma paisagem rurbana.

Antes da exposição do método com o qual se pretende verificar tal hipótese, necessita-se a abertura de um parêntese para a compreensão da utilização de determinados termos. Anoção de rurbano foi proposta inicialmente por Sorokin, Zimermann e Galpin, em 1930, a fim de definir as situações intermediárias encontradas em seu trabalho de definição de uma tipologia baseada nas categorias de rural e urbano. Segundo Santos (2006), Gilberto Freyre importou o termo rurban aportuguesando para rurbano e usando-o pela primeira vez na obra "Sociologia: introdução ao estudo dos seus princípios" de 1945. Ao utilizá-la, no entanto, Freyre confere a esta noção uma acepção distinta daqueles, entendendo este modo de vida misto como uma categoria autônoma:

\section{“(...) venho, no Brasil, procurando desenvol-}

ver [a noção de rurbano] para caracterizar situação mista, dinâmica e, repito, conjugal, fecundamente conjugal: terceira situação desenvolvida pela conjugação de valores das duas situações originais e às vezes contrárias ou desarmônicas, quando puras" (FREYRE, 1982, 82-3).

Em sua utilização atual, esta terceira categoria proposta por Freyre assume, no entanto, matizes diferenciados. José Graziano da Silva utiliza-se da noção de rurbano ou de "novo rural" para compreender o processo de urbanização do campo (GRAZIANO DA SILVA, J. 1997). Já Maria José Carneiro (1998) recorre a esta noção para descrever o surgimento de novas identidades rurais frente à divulgação de valores urbanos através da vulgarização do acesso a meios de comunicação e transporte - e a conseqüente redução das distâncias entre estes antigos extremos. Para Eli da Veiga, no entanto, rurbanos são "tanto os [municípios] que têm populações entre 50 e 100 mil, quanto os que têm menos de 50 mil, mas densidades superiores a 80 hab/km2"(VEIGA, 2001). Entretanto, independentemente de quais sejam os significados atribuídos ao rurbano sob a pena de tais autores, o emprego do conceito de rurbano apóia-se aqui na definição por Freyre (1982), que entende o rurbano como a conjugação entre os modos de vida rural e urbano.

O território, por sua vez, é lido como um "imenso depósito de signos, conscientemente deixados por quem nos precedeu" (SECCHI, 2006, p.15), cujo resultado é o produto de "um longo processo de seleção acumulativa" (SECCHI, 2006, p.16). Neste sentido, a paisagem é a camada deste território que nos é passível de apreensão pelo olhar, que estabelece, no entanto, devido à origem etimológica deste vocábulo-pagus, do latim do baixo império (CUNHA, 1986), que designa o território no qual se habita, a nação uma relação íntima com o "habitar", o "apropriar-se de", o "pertencer a" um território e, consequentemente, com os diferentes modos de vida. Ampliando-se a definição de Solà-Morales de paisagem urbana para a noção de paisagem de modo geral, temos: "conjunto dos lugares em que se vive, existe e sucede a vida (...), ao mesmo tempo, o meio e o resultado desta media- 
ção do fazer dos não lugares, lugares" (SOLAMORALES2002, p.110).

A averiguação da hipótese acima exposta exige a definição de um corpus cuja análise permita a comparação entre as duas situações; uma antes e outra após a elevação de um distrito rural a sede municipal. Para tanto, a pesquisa ora apresentada - de caráter exploratório - baseia-se em reflexões sobre um estudo de caso: a sede de um pequeno município rural inserido na Região Metropolitana de Maringá - Ângulo/PR, cuja população total é de apenas 2804 habitantes (IBGE, 2007) e a elevação do vilarejo à condição de sede municipal (cidade) deu-se há somente 16 anos atrás. Este período permite tanto a caracterização da situação anterior, por sua proximidade temporal, quanto a verificação das alterações na paisagem devido a sua sedimentação incipiente.

A caracterização de uma paisagem como rurbana exige, no mínimo, o reconhecimento nesta de características tanto urbanas quanto rurais. A fim de desvelar os aspectos rurais do modo de vida local inscritos na paisagem, optou-se por enfocar a relação entre as práticas sociais rurais na sede e a configuração de sua paisagem. Este enquadramento apóia-se na definição de Bourdieu (1979) de "modo de vida" (habitus) como princípio gerador e sistema classificatório das práticas sociais, ou seja, a "capacidade de produzir práticas e obras classificáveis [e, por outro lado, a] capacidade de diferenciar e de apreciar estas práticas e seus produtos" (BOURDIEU, 1979, p.190). Logo, observa-se que a verificação da relação entre a configuração da paisagem e o modo de vida exigiria tanto a identificação de práticas sociais rurais e de seus vestígios no espaço da sede, quanto a leitura destas práticas realizada por seus habitantes.

A abordagem da relação entre práticas sociais e a configuração do espaço urbano já fora realizada anteriormente. Neste âmbito, o enfoque aqui privilegiado baseia-se na metodologia proposta por Depaule (1999) que - com base na teoria de Bourdieu das práticas sociais como a interação entre um sistema de disposição (interiorizado pelo indivíduo através de sua educação e de sua história pessoal e, sobretudo, a de sua classe) e uma situação dada-define:

[...] é possível reconhecer a prática em suas demarcações, ou seja, nas manifestações concretas através das quais ela se afirma e deposita seus vestígios que são sempre significativos; e, de outro lado, a palavra do habitante revela as diferenças práticas e simbólicas segundo as quais os lugares são vividos (DEPAULE, 1999, p.168).

A investigação, por sua vez, dos aspectos urbanos insculpidos na paisagem de Ângulo exige a focalização de aspecto inerente ao espaço citadino. Tendo em vista o fato que a trama de espaços públicos é o cenário da manifestação dos valores urbanos coletivos (SENETT, 1998) e o lócus a partir do qual a cidade é apreendida (PANERAI, 1999), o estudo da morfogênese - entendida de acordo com a definição de Castex (1999) do traçado desta vila figura-se como o mais adequado para tal fim. Sob esta perspectiva, traz-se à luz o processo de transformação do traçado de Ângulo, comparando a sua situação antes e após a emancipação municipal e destacando suas propriedades distintivas.

Explicitados os métodos a serem utilizados, defende-se que, antes de empreender a verificação da hipótese postulada, é indispensável proceder à contextualização geral do processo histórico da ocupação do município estudado, abordada na seqüência.

\section{BREVE PANORAMA DA OCUPAÇÃO EM ÂNGULO - PR}

Até 1993, ano da implantação do município de Ângulo, o vilarejo homônimo pertencia ao território rural de Iguaraçu/PR. O referido vilarejo, no entanto, teve sua fundação em meados de 1940, quando três imigrantes russos compraram terras da Companhia Melhoramentos Norte do Paraná para fins de plantio de café e resolveram destinar parte da propriedade para o projeto de uma nova cidade (FERREIRA, 1996).

O projeto do loteamento inicial foi concebido em 1946 por Dimitri Novikov, engenheiro ucraniano, 
Paisagens rurbanas: a tensão entre práticas rurais e valores urbanos na morfogênese dos espaços públicos de sedes de Municípios rurais. Um estudo de caso

Gisela Barcellos de Souza

e implantado em 1948. Segundo o morador Raimundo Bianchini, que chegou na cidade em 1949 (entrevista cedida à autora em 28 de abril de 2006), quando os primeiros moradores - oriundos de diferentes regiões do país - chegaram, a cidade já contava com todos seus arruamentos abertos e com infra-estrutura de iluminação pública gerada por motor a óleo diesel. Ainda nos primeiros anos da vila, dois novos loteamentos foram acrescidos à ela: o Vila Mariana e o Vila Soledad (ESQ. 1).

Não obstante a importância que esta pequena vila pudesse ter para seus moradores, a ocupação des- te território continuaria vinculada ao plantio de café até meados da década de 1970, quando a situação de progressivo abandono da produção do café na região foi agravada com a geada de 1975. Comparando-se os dados do IBGE sobre a população total residente no Município de Iguaraçu - no qual o vilarejo de Ângulo compunha os dados da área rural - entre os anos de 1970 e 1980 (9.855 hab. e 6.526 hab., respectivamente), percebe-se que houve um decréscimo de $34 \%$ na população total do município. Neste mesmo intervalo temporal, a taxa de urbanização do município passou de $17,5 \%$ para $31,9 \%$ (IBGE, 1970 e 1980 ).

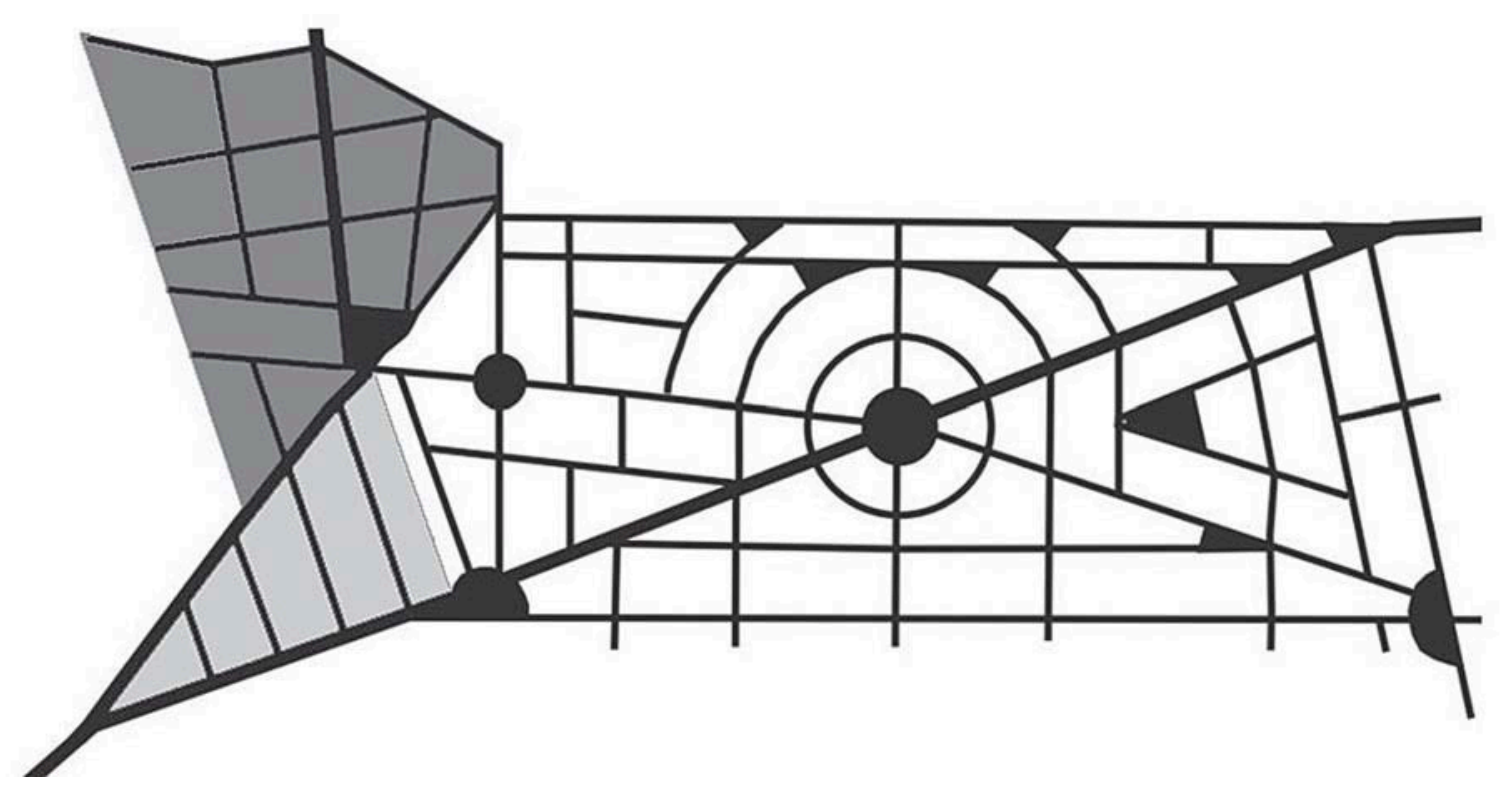

ESQUEMA 1: Núcleo inicial de Ângulo e suas expansões ainda na década de 1940: em branco, o loteamento inicial; em cinza escuro, a Vila Soledad e, em cinza claro, a Vila Mariana. Fonte e Elaboração: o autor.

Diversas foram as tentativas de buscar alternativas econômicas que viessem a preencher o vazio deixado pelo café. Dentre elas, o plantio do algodão acompanhado de forte êxodo rural que alterou a taxa de urbanização de $31,9 \%$ para $64,30 \%$ entre 1980 e 1991 - foi o que mais marcou o município. Tal fenômeno insere-se dentro do contexto de mudanças nas relações produtivas e trabalhistas estabelecidas no meio rural - que ocasionou a vinda significativa de trabalhadores rurais para a cidade -, como também da procura, por parte dos produtores rurais, dos benefícios ofe- recidos pelo distrito, como o acesso à energia elétrica e à telefonia (SOUZA et al., 2006a).

As pragas e o crescente desinteresse da indústria têxtil pelo produto nacional levaram os produtores locais a substituir progressivamente o plantio de algodão pelo cultivo mecanizado de soja e milho - que atualmente ocupam, respectivamente, $58 \%$ e $39 \%$ da área produtiva do território rural do município (EMATER, 2005) -, reduzindo ainda mais a oferta local de emprego e marcando o início do movimento 
migratório sazonal em Ângulo. Atualmente, todo ano, cerca de 10 a $15 \%$ da população municipal desloca-se para Minas Gerais e São Paulo para trabalhar na colheita do café e retorna a Ângulo somente após o término do trabalho (SOUZA et al., 2006b).

\section{PRÁTICAS RURAIS NO ESPAÇO URBANO E A CONFIGURAÇÃO DA PAISAGEM}

Apesar de o loteamento inicial da cidade de Ângulo ter sido totalmente implantado em 1948, este permaneceu em grande parte desocupado por quase 40 anos. A infra-estrutura de iluminação pública implantada nos primeiros anos da cidade se perdeu com o passar dos anos e com a falta de manutenção, os arruamentos do traçado original esmaeceram-se sob a expansão da vegetação e do plantio das chácaras que se sobrepuseram aos lotes e quadras (FOTO 1). Apenas com a emancipação do município e a necessidade de localização de diversas obras públicas voltou-se a incentivar a ocupação da porção leste da cidade, que permanecera por muito tempo desocupada.

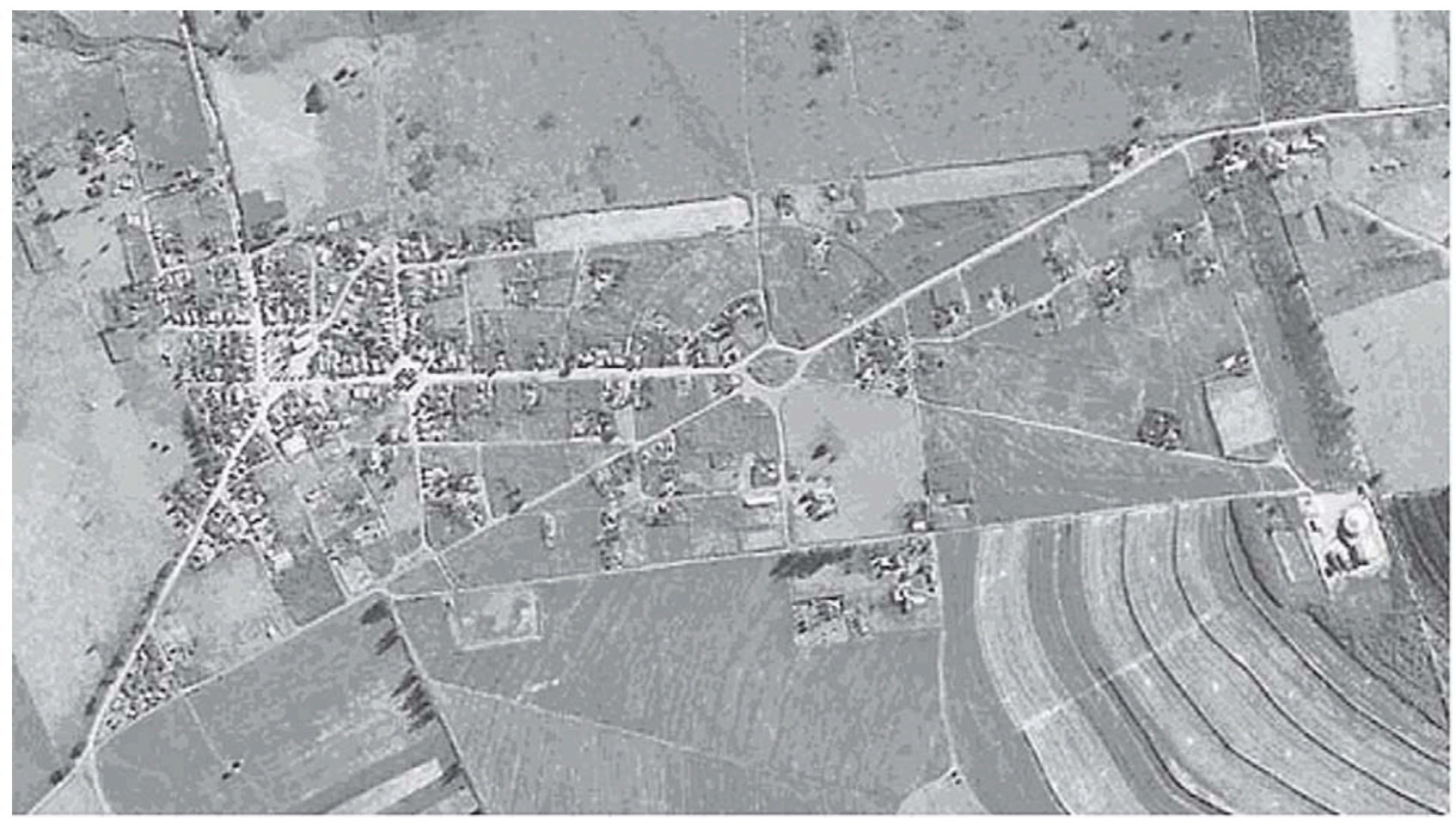

FOTO 1: Aerofoto de Ângulo em 1980. Note-se a ocupação concentrada a oeste (em torno da praça da igreja matriz)e o esmaecimento do traçado de 1948, na porção leste, sob a vegetação das chácaras que incorporaram suas quadras e arruamentos. Fonte: ITC, 1980.

A ocupação desta área da cidade deu-se de forma rarefeita e fora motivada, sobretudo, pelo acréscimo populacional que a sede do município recémemancipado recebeu entre 1991 e 2000 . A variação demográfica nestes anos nos setores censitários mostra que, enquanto os setores rurais apresentaram um decréscimo populacional de $-38 \%$ e $-10 \%$, a sede de Ângulo obteve um acréscimo de 39\%, elevando a taxa de urbanização do município para 75,7\% (IBGE, 1991 e 2000). O acréscimo populacional não garantiu, po- rém, a consolidação da vila projetada em 1946, pois, ainda hoje, $42 \%$ de seus lotes ainda estão vagos.

Juntamente com os proprietários e trabalhadores rurais vieram seus hábitos, que tiveram de ser conformados e moldados dentro dos contornos da malha urbana. Entre os lotes ocupados da cidade, por exemplo, em 4\% deles verificam-se a existência de galpões para armazenamento de implementos agrícolas contíguos a residências (SOUZA et al., 2006a). A concen- 
Paisagens rurbanas: a tensão entre práticas rurais e valores urbanos na morfogênese dos espaços públicos de sedes de Municípios rurais. Um estudo de caso

Gisela Barcellos de Souza

tração destes na região mais antiga da cidade (MAPA 1) e mais bem servida por infra-estrutura urbana explica-se pela vinda dos produtores rurais para a sede, sobretudo após a emancipação municipal, como já foi abordado. Visto que com o despovoamento das propriedades rurais se extinguiram as possibilidades de vigilância no meio rural, os novos residentes trouxeram consigo os galpões agrícolas, onde guardam os seus maquinários, além de grãos e agrotóxicos.

Se, por um lado, a co-existência dos galpões de implementos agrícolas com os demais usos urbanos é a que gera maiores impactos e conflitos - a proliferação de pragas urbanas, a contaminação do solo, entre outros (SOUZA et al., 2006a) -, por outro, a destinação de áreas dentro do perímetro urbano para fins de produção agropecuária é a mais freqüente. Atualmente, sob o total de parcelas da cidade (1050 lotes, entre ocupados e vagos), em 19\% há algum tipo de cultivo agrícola - dos quais $85,5 \%$ são destinados exclusivamente a tal fim - e em $4 \%$ há a criação de gado bovino.

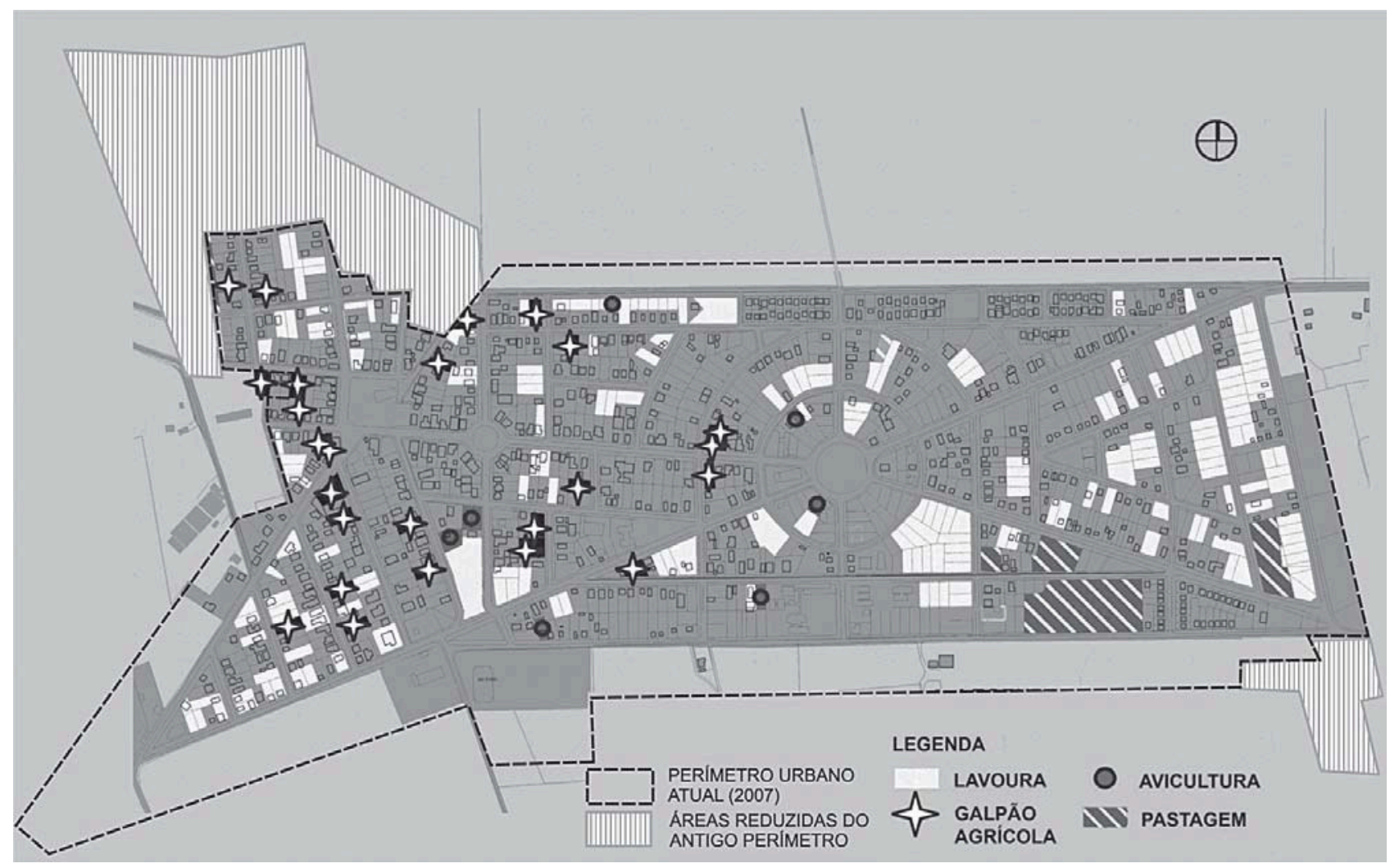

MAPA 1: Levantamento de Usos Agropecuários em Ângulo (sede) em 2006. Fonte: Adap. do autor com base em SOUZA et al., 2006a e ÂNGULO, 2007.

Este tipo de atividade ocorre significativamente em maior número na porção leste da cidade - a de ocupação mais recente, na qual a disponibilidade de infra-estrutura urbana é a mais deficitária. Alguns destes cultivos são de propriedade própria - destinandose para tal, em geral, dois lotes urbanos, ou seja, $1200 \mathrm{~m}^{2}$ -, porém é significativo o número de arrendamentos, por parte da população de menor renda, de lotes urba- nos para plantio de subsistência, visto que algumas famílias são proprietárias de quadras inteiras nesta porção da cidade (SOUZA et al., 2006a).

Os vestígios da inscrição das práticas sociais no espaço resumem-se ao que fora acima descrito, parte-se agora para a análise de como esta é lida - e classificada - por seus habitantes. Para tanto, apóia-se 
em dois documentos realizados para elaboração do Plano Diretor Participativo de Ângulo (elaborado através de projeto de extensão contemplado pelo Edital MCT/ MCidades/CNPq n ${ }^{\circ}$ 060/2005): a Leitura Comunitária - que apresenta todas as atas do processo participativo constituído por 6 oficinas e 5 audiências públicas -; assim como, a Lei do Plano, fruto desta participação. Entende-se que, ao representar uma síntese coletiva sobre aspectos diversos do município, cuja construção envolveu os diversos setores da sociedade, a análise transversal deste documento - sob o enfoque do surgimento o tema "usos agropecuários dentro do perímetro urbano" no processo participativo - permite revelar as relações simbólicas entre estas práticas e os espaços nos quais elas se inscrevem. A importância que esta temática teve no processo no debate é testemunhada, também, na Lei do Plano por seu grau de interferência na definição do Macrozoneamento e pela proposição de um programa específico para sua regulamentação.

Em todas as audiências públicas, os temas re- lativos ao espaço rural mostraram-se de suma importância para o contexto local, congregando grande número de interessados em seu debate em diferentes grupos (SOUZA et al., 2006b). Paralelamente, o espaço urbano nestas discussões foi pensado, por diversas vezes, sob a ótica das atividades rurais que se lhe sobrepõem.

A temática dos galpões de implementos agrícolas e de sua relação conflituosa com as demais atividades urbanas foi levantada já na primeira oficina de capacitação (realizara em 27 de abril de 2006), em meio ao levantamento de temas relevantes para a construção do Plano Diretor de Ângulo. Na segunda oficina de capacitação - destinada, entre outros, à definição dos temas para o debate público (realizada em junho de 2006) -, a questão dos vazios urbanos de Ângulo foi enfocada de forma diferenciada pelos representantes. Ao mesmo tempo em que a presença de cultivos de café com uso de agrotóxicos na parte mais antiga e central da cidade gerava grande polêmica entre os presentes, a presença dos cultivos na parte leste

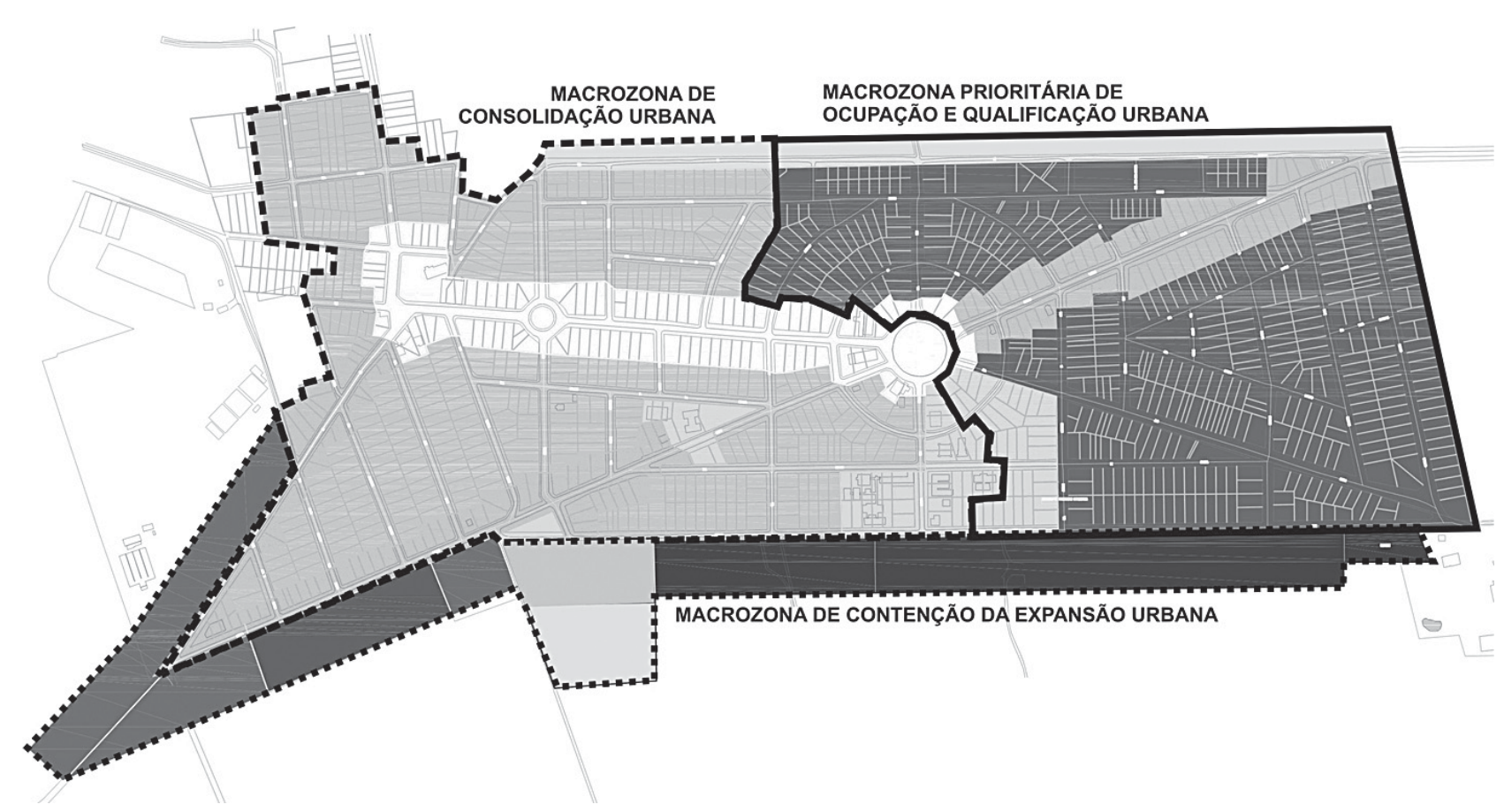

MAPA 2: Macrozonas Urbanas do Plano Diretor de Ângulo e Áreas dos Parâmetros de Uso e Ocupação definidos para área urbana. As áreas em cinza escuro correspondem aos locais em que os usos agropecuários foram permitidos e em cinza claro onde estes foram proibidos. Fonte: Adap. do autor, a partir de ÂNGULO, 2006 e 2007. 
Paisagens rurbanas: a tensão entre práticas rurais e valores urbanos na morfogênese dos espaços públicos de sedes de Municípios rurais. Um estudo de caso

Gisela Barcellos de Souza

da cidade parecia motivar menor interesse de discussão, sendo defendida por alguns como alternativa de complementação alimentar para moradores de baixa renda (SOUZA et al., 2006b).

As tonalidades diferenciadas da leitura destas práticas rurais no espaço urbano manifestaram-se, sobretudo, na definição dos objetivos para porções específicas do território urbano - através do Macrozoneamento e dos Parâmetros de Uso e Ocupação. Enquanto na porção oeste da cidade - o centro comercial - os usos agropecuários foram proibidos (cf. MAPA 2); na porção leste - onde se concentra a população de baixa renda -, a agricultura urbana e a produção granjeira para consumo próprio foram permitidas em até $1200 \mathrm{~m}^{2}$ e fomentadas através de programa específico criado na Lei do Plano e vinculado ao IPTU progressivo (cf. SOUZA et al., 2007b).

A partir do exposto, percebe-se o quão relevantes são as práticas rurais inscritas no espaço urbano de Ângulo para o modo de vida e a paisagem local. Estas práticas configuram a paisagem do espaço citadino, imbricam-se na história da vila e revelam seus diferentes contornos e significados a partir da leitura de seus habitantes. A representação coletiva destas práticas no imaginário local permite desvelar as relações distintas que as atividades rurais estabelecem com os traços citadinos. Na parte antiga da cidade, os valores urbanos apresentam-se mais sedimentados e, portanto, nesta os usos rurais são percebidos como conflituosos; por outro lado, na área urbana em consolidação, onde reside a população de baixa renda e praticase com maior intensidade a agricultura urbana, esta possível oposição parece dirimida.

\section{MORFOGÊNESE DE UM TRAÇADO INTER- MITENTE}

A forma urbana revela diferentes tempos de construção e inscrição; não se trata de uma configuração estática, mas sim de uma morfologia cujos contornos estão em contínua transformação e mutação. Neste contexto, o traçado - a res pública da cidade, que, diferentemente do espaço regido pela propriedade privada, apresenta-se menos suscetível a alterações em curto prazo - é freqüentemente associado à idéia de permanência (ROSSI, 2001). Entretanto, em Ângulo, a trama de espaços públicos da cidade mostrou-se flexível no tempo, ocasionando um fenômeno pouco comum num curto período de tempo: a redução e esmaecimento do traçado da cidade e sua posterior re-inscrição.

Tal processo caracteriza-se por três momentos. No primeiro período, o da implantação do projeto de Dimitri Novikov, todos os arruamentos previstos no loteamento de 1946, bem como nos de 1948, foram abertos, a iluminação pública fora instalada na vila, edificaram-se alguns comércios e serviços - como uma máquina de arroz, uma sorveteria e um restaurante $-\mathrm{e}$ a primeira escola pública fora inaugurada. No segundo, a ocupação urbana concentrou-se no entorno da praça da Igreja Matriz, permanecendo o restante da cidade desocupado. O traçado e a infra-estrutura original, como já foi dito, desapareceram face à falta de manutenção e à instauração de cultivos sobre o antigo loteamento. Por último, o processo de esvaziamento do campo e o estabelecimento da população rural dentro do perímetro da cidade, durante a década de 1980 e, principalmente, a 1990, justificou a ocupação do restante da cidade e a recuperação de parte do traçado original.

Neste processo intermitente de construção, esmaecimento e recuperação do traçado da cidade, poucas alterações significativas ocorreram no projeto implantado na década de 1940, e, neste sentido, o reconhecimento de duas questões é necessário para sua compreensão.

A primeira delas é a polarização da ocupação exercida pela Igreja Matriz, implantada no loteamento Vila Soledad, acrescido em 1948 ao loteamento inicial de Ângulo (ESQ. 2). A presença desta igreja - cuja construção foi empreendida por membros da comunidade na primeira década da cidade (SOUZA et al., 2006a) - exerceu tamanha influência sobre nos primeiros anos de ocupação do povoado que foi capaz de provocar uma mutação no projeto original da cidade, fazendo com que os seus dois acréscimos - a Vila Soledad e a Vila Mariana, ambas de 1948 - viessem a obter maior importância no vilarejo. Frente à força 
exercida por este símbolo religioso, as parcelas no loteamento de 1946 perderam seu interesse para construção de moradias, sendo as já compradas destinadas ao plantio e configurando, desta forma, o quadro descrito no segundo período da morfogênese do traçado de Ângulo.

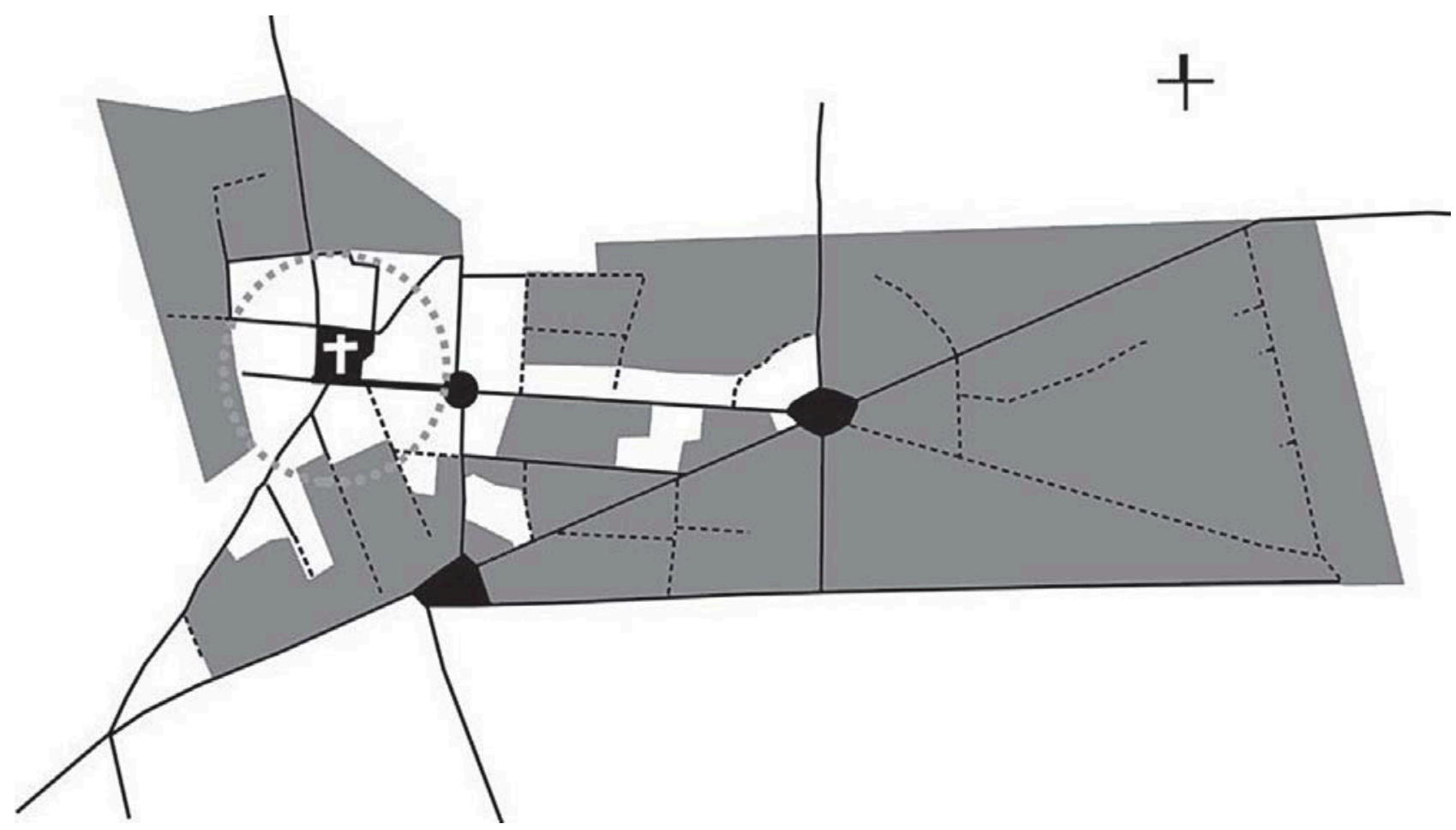

ESQUEMA 2: Ângulo e a relação entre as práticas rurais e trama de espaços públicos no ano de 1980: em cinza escuro, a presença de cultivos e pastagens; em linha preta contínua, os arruamentos e praças; em linha preta tracejada, as trilhas e/ou carreadores. Destaque dado à igreja, cruz branca, e ao raio de 150m, circunferência em cinza claro. Fonte e Elaboração: o autor a partir de ITC, 1980.

A segunda questão a ser destacada aparece como reação à primeira: a revalorização do projeto original de Ângulo. Percebe-se na história recente da cidade, sobretudo após a emancipação do município, a busca pela recuperação do projeto do loteamento de 1946.

Certamente, o êxodo do meio rural, que ocorreu ao longo da década de 1980, e o acréscimo populacional significativo que a cidade de Ângulo recebeu, fomentou a expansão da cidade a leste que caracteriza o terceiro período. Esta ocupação ocorreu, inicialmente, de forma adjacente às áreas já ocupadas dos loteamentos e promoveu, pouco a pouco, a ocupação da porção leste da cidade.
Entretanto, com a emancipação do município, a ocupação da parte leste passou a ser revalorizada e fomentada pela municipalidade, assumindo uma importância cívica na cidade. Nela foram implantados, além dos novos conjuntos habitacionais, os equipamentos comunitários e instituições públicas - como a escola, a creche, o núcleo de saúde, a casa da geração de renda, entre outros (SOUZA et al., 2006a) -, demonstrando uma busca de conferir representatividade simbólica ao espaço central do loteamento de 1946, tal qual especificado em seu projeto inicial (MAPA 3). Esta porção central de Ângulo passou a ser chamada de centro pela população local; entretanto a centralidade comercial da cidade continua no entorno da Praça da Igreja Matriz. 
Paisagens rurbanas: a tensão entre práticas rurais e valores urbanos na morfogênese dos espaços públicos de sedes de Municípios rurais. Um estudo de caso

Gisela Barcellos de Souza

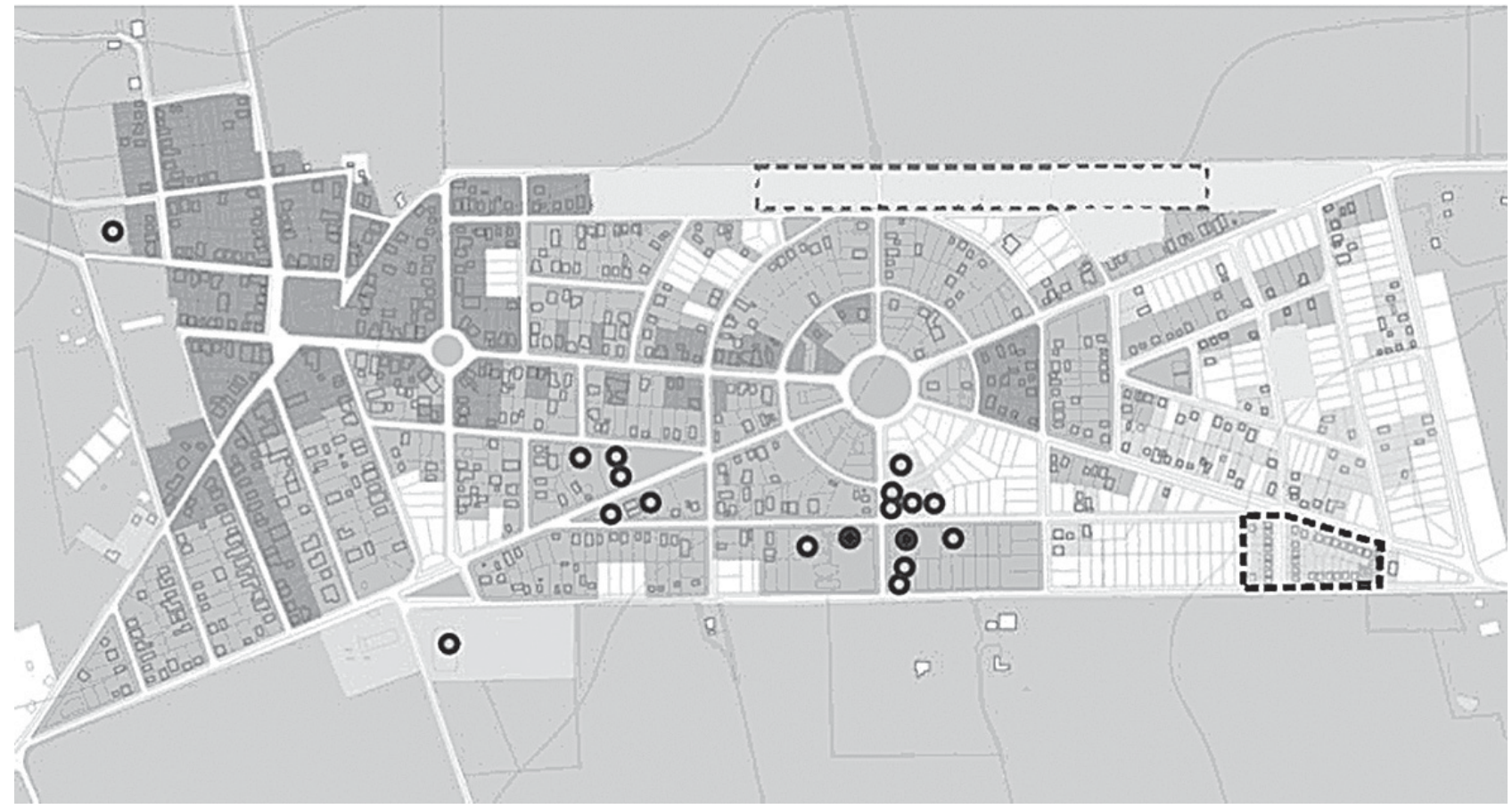

MAPA 3: Relação entre a evolução urbana do Distrito Sede de Ângulo e a localização de instituições públicas e conjuntos habitacionais. Em cinza escuro estão representadas as áreas ocupadas até 1980; em cinza médio as áreas ocupadas entre 1980 e 1990 ; em cinza claro destacam-se as áreas ocupadas após 1990. Os círculos em cinza pontuam as instituições públicas implantadas após a emancipação e os círculos em preto as implantadas anteriormente. Destaca-se em pontilhado cinza médio os conjuntos habitacionais construídos nos primeiros anos da emancipação e em preto o construído em 2002. Fonte: Org. o autor a partir de SOUZA et al, 2006 a.

A importância cívica que o centro geográfico assumiu na cidade recém emancipada foi reforçada pela transferência, em 2000, da Prefeitura e da Câmara Municipal, antes localizadas junto à Praça da Igreja Matriz, para o local onde fora edificada a primeira escola local, em 1956, destruída em incêndio após quatro anos de funcionamento.

A recuperação de um traçado e de um parcelamento antes imersos em cultivos agropecuários, a busca por fomentar sua povoação e sua re-significação demonstram a revalorização dos aspectos urbanos e relacionam-se com o surgimento de novos equipamentos cívicos oriundos da emancipação do município. Percebe-se, em sua morfogênese, a capacidade do traçado de Ângulo em congregar e sintetizar valores urbanos. $\mathrm{O}$ antigo vilarejo pertencente ao espaço rural de Iguaraçu, ao ser transformado em sede do novo município, reconquista seus espaços públicos urbanos esmaecidos pela apropriação rural. A lei e a pro- priedade pública são o que garante a possibilidade deste resgate: "A lei, cumprida ou burlada, arcaica ou reajustada, incide sobre o convívio dos cidadãos (...). Regula de diversas maneiras e para diferentes conflitos os espaços comuns urbanos." (MARX, 1989, p.17).

\section{CONSIDERAÇÕES FINAIS}

A partir do exposto, fica evidente a convivência simultânea - espacial e temporalmente - de práticas rurais e valores urbanos no espaço contido pelo perímetro da sede de Ângulo. Esta coexistência e sua manifestação no espaço urbano foram, conforme explicitado, construídas historicamente. As práticas rurais e os valores urbanos sintetizados pelo traçado original imbricam-se de forma particular e permitem a constituição de uma paisagem rurbana, na qual o espaço público desaparece e reaparece, num rearranjo entre a lei citadina e o modo de vida rural. Neste aparente antagonismo entre ruralidade e urbanidade surge uma 
paisagem que concilia ambos num degradé instável definido através de uma legitimidade cambiável, fazendo com que ora um ou outro se sobressaia.

Estas asserções não são certamente, exclusivas a Ângulo, mas sim passíveis de serem verificadas em outras tantas vilas brasileiras promovidas à condição de cidades ao serem transformadas em sede de municípios. Nestas há uma recorrente reordenação de papeis entre a urbanidade - promovida, entre outros, pela representatividade da estrutura administrativa e as instituições estatais - e a ruralidade local, caracterizando, desta forma, um modo de vida rurbano e sua paisagem correspondente.

\section{REFERÊNCIAS}

ÂNGULO. Lei $n^{\circ} 04$ de 10 de Outubro de 2006. Plano Diretor Participativo de Ângulo. Ângulo: Câmara Municipal, 2006.

ÂNGULO. Lei $n^{\circ} 10$ de 4 de Marco de 2007. Lei do Ordenamento Territorial de Ângulo. Ângulo: Câmara Municipal, 2007.

BOURDIEU, P. La Distanction. Paris: Les Editions de Minuit, 1979.

CARNEIRO, M. J. Ruralidade: novas identidades em construção. Estudos Sociedade e Agricultura, Rio de Janeiro, n. 11, p. 53-75, outubro. 1998.

DEPAULE, La pratique de l'espace urbain. In: PANERAI et al. Analyse Urbaine. Paris: Éditions Paranthèses, 1999, p.159-185.

PANERAI et al. Analyse Urbaine. Paris: Éditions Paranthèses, 1999.

FERREIRA, J. C. V. O Paraná e seus Municípios. 19 ed. Maringá: Memória Brasileira, 1996.

FREYRE, G. Rurbanização: Que é? Recife: Massangana, 1982.

MARX, M.. Nosso chão: do sagrado ao profano. São
Paulo: Nobel, 1989.

ROSSI, A. L'Architecture de la Ville. Paris: InFolio, 2001.

SANTOS, R.; SANTOS, R. N. Rurbanização como estilo de desenvolvimento em Gilberto Freyre. In: AMODEO, ALIMONDA. (Org.). Ruralidades, capacitação e desenvolvimento. 1 ed. Viçosa: UFV/CPDA, 2006, v. 1, p. 27-43.

SECCHI, B. Primeira Lição de Urbanismo. São Paulo: Perspectiva, 2006.

SENNET, Richard. O declínio do homem público. As tiranias da intimidade. São Paulo: Companhia das Letras, 1998.

SIEVERTS, Thomas. Entre-ville. Une lecture de la Zwischenstadt. Paris: Editions Parenthèses, 2004.

GRAZINANO DA SILVA, José. O Novo Rural Brasileiro. Nova economia, Belo horizonte, v.7, n.1, p.4381, maio.1997.

SOLÀ-MORALES, I. Paisajes. In: Territórios. Barcelona: Gustavo Gili, 2002.

SOUZA, G. B. et al. Leitura Técnica do Município de Ângulo. Plano Diretor Participativo. Ângulo: [s. n.], 2006 .

SOUZA, G. B. et al. Leitura Comunitária do Município de Ângulo. Plano Diretor Participativo. Ângulo: [s. n.], $2006 \mathrm{~b}$.

SOUZA, G. B. et al. Implementação do Estatuto da Cidade em Municípios Rurais, de Pequeno Porte Populacional, Inseridos em Região Metropolitana: Limites e Possibilidades. In: II SEMINÁRIO NACIONAL METRÓPOLE: GOVERNO, SOCIEDADE E TERRITÓRIO. Participação Social e Dinâmicas Espaciais, 2007, Rio de Janeiro. Anais... Rio de Janeiro: CEPUERJ, 2007a.

SOUZA, G. B. et al. De Vacante a Ocupado: A incor- 
Paisagens rurbanas: a tensão entre práticas rurais e valores urbanos na morfogênese dos espaços públicos de sedes de Municípios rurais. Um estudo de caso

Gisela Barcellos de Souza

poração da Agricultura Urbana no Planejamento Municipal. O caso de Ângulo/PR. In: II SEMINÁRIO SOBRE REGENERAÇÃO AMBIENTAL DE CIDADES - ÁGUAS URBANAS, 2007, Londrina. Anais... Londrina: Eduel, 2007b.

VEIGA, J. E. Desenvolvimento Territorial do Brasil: do entulho varguista ao ZEE. In: XXIX ENCONTRO NACIONAL DE ECONOMIA, 2001, Salvador. Anais... Campinas, SP: ANPEC, 2001. v. 1. p. 1-20. 